\title{
MORPHOLOGICAL PATTERN OF BONE MARROW IN MULTIPLE MYELOMA- A DESCRIPTIVE STUDY
}

\author{
Deepthi Raj M. L', Surupa Susan Kurien²
}

${ }^{1}$ Assistant Professor, Department of Pathology, Government Medical College, Trivandrum, Kerala. ${ }^{2}$ Assistant Professor, Department of Pathology, Government Medical College, Trivandrum, Kerala.

\section{ABSTRACT}

\section{BACKGROUND}

Multiple myeloma is a bone marrow based plasma cell neoplasm that often presents with multifocal and disseminated involvement. Not surprisingly bone marrow examination is a key to its diagnosis along with laboratory and clinical data. Morphology of plasma cells assumes significance along with plasma cell quantity in distinguishing multiple myeloma from reactive plasmacytosis. At times the heterogeneity in plasma cell morphology leads to misdiagnosis as other neoplasms like lymphomas.

The present study is an attempt to evaluate the various morphological patterns seen in bone marrow of cases diagnosed as multiple myeloma.

\section{MATERIALS AND METHODS}

Bone marrow of 100 consecutive cases reported as multiple myeloma in the Department of Pathology, Government Medical College, Trivandrum was analysed. The data collected included demographic profile of the patient, clinical presentation and relevant haematological and biochemical values. Quantitative and qualitative assessment of plasma cells in bone marrow was done.

\section{RESULTS}

The median age of diagnosis was 58 years with a male predominance. The dominant clinical presentation was bone pain. Peripheral smear examination showed increased rouleaux formation $(100 \%)$ and normocytic normochromic anaemia (87\%) with a single case of plasma cell leukaemia. Bone marrow study revealed that majority of the cases showed a plasma cell burden between $20 \%$ - 50\% and were predominantly of mature plasma cell type. The morphologic variations of plasma cells noted were flame cells, multinuclearity, morula cells and Dutcher body. The most common pattern of infiltration seen on trephine biopsy was the nodular pattern.

\section{CONCLUSION}

A detailed examination of the bone marrow including a qualitative assessment of plasma cell morphology and the pattern of infiltration remains a key to the diagnosis and prognostication of cases of multiple myeloma.

\section{KEYWORDS}

Multiple Myeloma, Bone Marrow, Morphology, Plasmablastic.

HOW TO CITE THIS ARTICLE: Raj DML, Kurien SS. Morphological pattern of bone marrow in multiple myeloma- a descriptive study. J. Evolution Med. Dent. Sci. 2017;6(69):4922-4924, DOI: 10.14260/Jemds/2017/1067

\section{BACKGROUND}

Multiple myeloma is a disease resulting from proliferation in the bone marrow of terminally differentiated $\mathrm{B}$ cells that secrete a single homogeneous immunoglobulin called $\mathrm{M}$ protein ${ }^{1}$. It is a multifocal neoplasm with a disseminated involvement of bone marrow in majority of cases. Primarily a disease of the elderly with a median age of 70 years, it constitutes $10 \%-15 \%$ of haematological neoplasms.

Bone marrow examination is an important part of the diagnostic criteria, which along with other laboratory tests help to establish the diagnosis. However, the findings in marrow can be highly variable with plasma cell percentage often ranging from 30 to 90 . There can also be variability in the plasma cell morphology.

Financial or Other, Competing Interest: None.

Submission 02-08-2017, Peer Review 19-08-2017,

Acceptance 21-08-2017, Published 28-08-2017.

Corresponding Author:

Dr. Surupa Susan Kurien,

1 D Avenue Rejency,

Adjacent St. Mary's Church,

Pattom P.O. Thiruvananthapuram-695004,

Kerala.

E-mail: surupasusan@gmail.com

DOI: $10.14260 /$ jemds $/ 2017 / 1067$
These include nucleocytoplasmic asynchrony, marked pleomorphism, multinuclearity, nuclear lobation, phagocytosis by myeloma cells and the presence of mitotic figures $^{2}$. These qualitative changes are helpful in distinguishing neoplastic plasma cell proliferations from reactive plasmacytosis, which can present with significant plasmacytosis. Nuclear cytoplasmic asynchrony has been described as an important morphologic characteristic in multiple myeloma. ${ }^{3}$

The bone marrow aspirate is also valuable in determining the prognosis of the patient depending upon the percentage of plasma cells and degree of dysplasia. ${ }^{4}$

Bone marrow biopsy similarly helps in diagnosis and prognostication. The 3 major patterns seen on biopsy are- (1) Interstitial, (2) Nodules or broad bands and (3) A packed marrow. ${ }^{5}$ These patterns also correlate well with the prognosis with the diffuse pattern exhibiting the worst prognosis followed by the nodular patterns.

The present study attempts to elucidate the morphology of multiple myeloma in bone marrow aspirates and biopsy.

\section{MATERIALS AND METHODS}

A descriptive study was conducted in the Clinical Pathology Division of Department of Pathology at Government Medical College, Trivandrum; 100 consecutive cases reported as 
multiple myeloma by bone marrow aspiration alone or along with bone marrow trephine was included in the study.

Basic haematological values were recorded. Peripheral smear examination and bone marrow examination was done in detail. Data of relevant biochemical tests and radiological findings were obtained.

The bone marrow aspirate smears were stained with Leishman's stain. The percentage of plasma cells on bone marrow aspirates was assessed and the patients were staged as I (<20\%), II (20\% - 50\%) and III (> 50\%). A morphological assessment of the plasma cells was done and plasma cells were categorised as mature, intermediate, immature and plasmablastic. Different growth patterns on bone marrow biopsy sections were also studied and were classified as interstitial, nodular and packed. The percentage of cases in each category was calculated.

Chi-square test was done to determine the relationship between plasma cell morphological type and plasma cell burden (\%) using SPSS version 20.

The patients were followed up for a minimum period of 6 months.

\section{RESULTS}

Multiple myeloma was diagnosed in a wide age range of 26 to 82 years with a median age of 58 years. There was a male predominance with a male-to-female ratio of 1.38: 1. Majority of the patients presented with bone pain. The laboratory tests consistently revealed anaemia and raised ESR in all cases with a median $\mathrm{Hb}$ value of $8.35 \mathrm{~g} / \mathrm{dL}$ and median ESR of 105 $\mathrm{mm} / \mathrm{hr}$. Total leucocyte count and platelet counts were found to be within normal limits in majority of cases.

Increased rouleaux formation was observed on peripheral smear examination in all cases; $87 \%$ of the cases showed a normocytic normochromic anaemia.

One case showed atypical plasma cells in the peripheral blood with differential count $<20 \%$. Single case of primary plasma cell leukaemia was also reported with more than $20 \%$ plasma cells in the peripheral smear.

Bone marrow aspiration was done in all the cases. The disease was classified as stage I $(<20 \%)$, stage II $(20 \%$ $50 \%$ ) and stage III ( $>50 \%$ ) based on the percentage of plasma cells in the bone marrow. Majority of the cases were grouped into stage II disease (59\%).

Based on the morphology of plasma cells cases were classified as mature (42\%), intermediate (40\%), immature $(14 \%)$ and plasmablastic (4\%) myeloma types. Majority of cases came under mature myeloma type. Plasmablastic myeloma type was noted in $4 \%$ of cases only. The morphologic variations of plasma cells noted were flame cells, multinuclearity, morula cells and Dutcher body (Table 1).

\begin{tabular}{|c|c|c|}
\hline Morphology & No. of Cases & Percentage \\
\hline Multinuclearity & 56 & $56 \%$ \\
\hline Flame cells & 9 & $9 \%$ \\
\hline Morula cells & 8 & $8 \%$ \\
\hline Dutcher body & 5 & $5 \%$ \\
\hline \multicolumn{3}{|c|}{ Table 1 } \\
\hline
\end{tabular}

One of the peripheral smears showed atypical plasma cells along with bizarre and multinucleated cells in the bone marrow aspirate and was diagnosed as anaplastic myeloma (Figure 1).

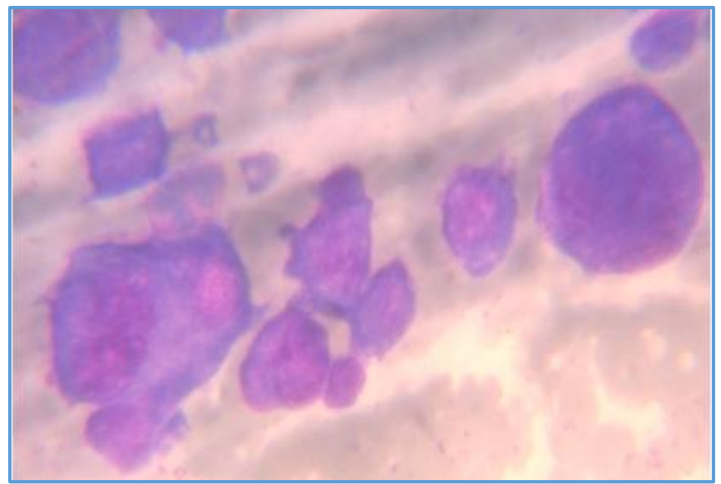

Figure 1. Anaplastic Myeloma (100X)

Bone marrow trephine biopsy was available in 84 cases; 3 types of growth patterns were noted: interstitial, nodular and packed with nodular pattern constituting maximum number of cases (Table 2) (Figure 2).

\begin{tabular}{|c|c|c|}
\hline Type & Number of Cases & Percentage \\
\hline Interstitial & 30 & $35.7 \%$ \\
\hline Nodular & 32 & $38.1 \%$ \\
\hline Packed & 22 & $26.2 \%$ \\
\hline \multicolumn{3}{|c|}{ Table 2} \\
\hline
\end{tabular}

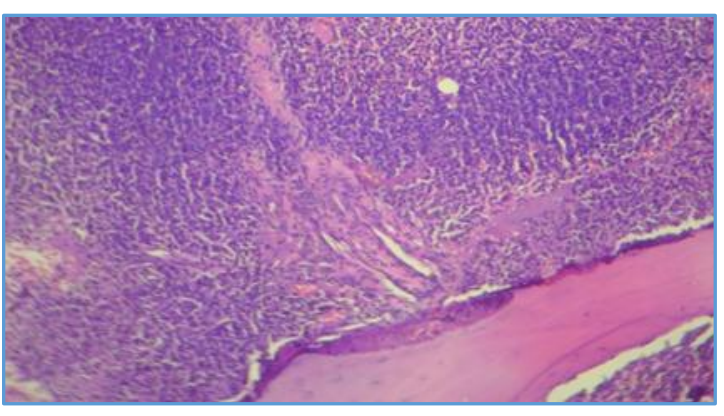

\section{Figure 2. Bone Marrow Trephine Biopsy showing Complete Replacement of Normal Elements by Plasma Cells (Packed Type) 40X}

Extramedullary involvement was noted in $3 \%$ of cases. The extramedullary sites were lymph node in 2 cases and soft tissue in 1 case.

On assessing the correlation between plasma cell morphology and stage according to plasma cell burden, crosstabulation suggested significant relation between morphology and stage (Table 3), but statistical significance could not be proven on applying the Chi-square test $(\mathrm{p}$ value $=$ 0.804).

\begin{tabular}{|c|c|c|c|}
\hline \multirow{2}{*}{ Myeloma Type } & \multicolumn{3}{|c|}{ Pathological Stage } \\
\cline { 2 - 4 } & I & II & III \\
\hline Mature & $7.1 \%$ & $66.7 \%$ & $26.2 \%$ \\
\hline Intermediate & $10.0 \%$ & $65.0 \%$ & $25.0 \%$ \\
\hline Immature & $7.1 \%$ & $50.0 \%$ & $42.9 \%$ \\
\hline Plasmablastic & $0.0 \%$ & $50.0 \%$ & $50.0 \%$ \\
\hline \multicolumn{4}{|c}{ Table 3 } \\
\hline
\end{tabular}

On follow up, 38 patients expired, 22 patients were lost for follow up.

\section{DISCUSSION}

In our study, the median age of diagnosis observed was 58 years with a male predominance. Bone pain was the dominant clinical presentation. A raised ESR and normocytic normochromic anaemia with rouleaux formation was seen in most cases, while total leukocyte counts and platelet counts were relatively normal. 
In bone marrow aspirate, the plasma cell percentage varied from $12 \%$ to $90 \%$. The diagnostic criteria put forward by the Myeloma Working Group, sets $10 \%$ as the minimal level of clonal plasma cells required in the marrow along with the presence of myeloma defining events.

In the present study, most of the patients had mature $(42 \%)$ or intermediate type of myeloma (40\%). Similarly, in a study by Griepp et al, the maximum number of cases were of intermediate type (38\%) followed by mature, immature and plasmablastic types with a proportion of $28 \%, 19 \%$ and $15 \%$ respectively. ${ }^{6}$ In our study, plasmablastic myeloma was seen only in $4 \%$ of patients and all of them expired within the period of followup. Similar poor outcome was observed by Carter et al in their study where the plasmablastic group had an estimated median survival of 10.9 months compared to 32.2 months for immature and 60 months for mature types. ${ }^{7}$

$50 \%$ of myeloma cases with plasmablastic morphology in our series showed stage III disease with a plasma cell burden more than $50 \%$. A study by Subramanian et al showed significant correlation between poorly differentiated plasma cell morphology and increased plasma cell burden in the marrow. $^{8}$ In our study even though cross-tabulation suggested significant relation between morphology and stage, statistical significance could not be proven due to the limited sample size of 100 cases.

Mutinuclearity of plasma cells were noted in $56 \%$ of cases, but showed no preponderance to any morphological class, while Bartl et al in a study included them under polymorphous myeloma of intermediate grade. ${ }^{9}$

Among the 84 patients having a bone marrow biopsy, we observed that nodular pattern of plasma cell infiltration was the predominant pattern with $38.1 \%$ cases. Interstitial pattern was noted in $35.7 \%$ and packed marrow in $26.2 \%$. A study by Chen et al on the other hand observed nodular pattern in $35.1 \%$, interstitial pattern in $16 \%$ and packed marrow in $49 \%,{ }^{10}$ while interstitial pattern was the most dominant pattern accounting for $52 \%$ of cases in a study by Al-Quran et al.11

In the present study, there was a case of anaplastic myeloma which showed extramedullary involvement. This is in concurrence with the finding by Bangerter et $\mathrm{al}, 12$ who observed in their study that majority of the plasmacytomas with extramedullary presentation showed anaplastic morphology. Foucar et al also reported 2 similar cases of anaplastic myeloma with extramedullary involvement showing primitive appearing anaplastic cells both in bone marrow and in extramedullary site. ${ }^{13}$ When they occur solely in extramedullary sites, anaplastic myelomas can be mistaken for other poorly differentiated neoplasms. Recognising plasmacytic differentiation in some cells and appropriate use of immunostains helps in overcoming the diagnostic difficulty. Anaplastic myeloma has got an aggressive clinical course. Our patient also expired within 5 days after the diagnosis was made.

Only $3 \%$ of patients in the series had extramedullary involvement at the time of diagnosis with 2 out of 3 cases presenting in lymph node and one in the soft tissue. According to Chen et al, soft tissue was the commonest site of involvement in extramedullary disease. ${ }^{14}$ In the study by Bangerter et al on extramedullary plasmacytomas, skin was the commonest site followed by lymph node.

\section{CONCLUSION}

In spite of advancements in the laboratory diagnosis of multiple myeloma and evolving criteria, a detailed bone marrow examination remains the cornerstone to its diagnosis. This includes the quantitative assessment of plasma cell burden in the marrow and also significantly a qualitative assessment of plasma cell morphology and its infiltrative pattern, which has bearing on the diagnosis as well as prognosis of the patient. Our study was an attempt to characterise in detail these bone marrow patterns and morphology in plasma cell myeloma.

\section{REFERENCES}

[1] Swerdlow SH, Campo E, Harris NL, et al. WHO classification of tumours of haematopoietic and lymphoid tissues. IARC: Lyon 2008;10:200-13.

[2] Bain B, Clark D, Wilkins B. Bone marrow pathology. Black Well publishing Chichester, 2010;7:421-60.

[3] Bernier GM, Graham RC. Plasma cell asynchrony in myeloma: correlation of light and electron microscopy. Semin Hematol 1976;13(3):239-45.

[4] Pasqualetti P, Casale R, Collacciani A, et al. Multiple myeloma: relationship between survival and cellular morphology. Am J Hematol 1990;33(2):145-7.

[5] Barti R, Frisch B, Diem H, et al. Bone marrow histology and serum beta 2 microglobulin in multiple myelomaa new prognostic strategy. Eur J Haematol Suppl 1989;51:88-98.

[6] Greipp PR, Raymond NM, Kyle RA, et al. Multiple myeloma: significance of plasmablastic subtype in morphological classification. Blood 1985;65(2):30510.

[7] Carter A, Hocherman I, Linn S, et al. Prognostic significance of plasma cell morphology in multiple myeloma. Cancer 1987;60(5):1060-5.

[8] Subramanian R, Basu D, Dutta TK. Prognostic significance of bone marrow histology in multiple myeloma. Indian J Cancer 2009;46(1):40-5.

[9] Bartl R, Frisch B, Fateh-Moghadam A, et al. Histologic classification and staging of multiple myeloma. A retrospective and prospective study of 674 cases. Am J Clin Pathol 1987;87(3):342-55.

[10] Chen HS, Liu EB, Wang TT, et al. Morphologic and clinical study of 131 cases of plasma cell myeloma. Zhonghua Bing Li Xue Za Zhi 2004;33(1):44-8.

[11] Al-Quran SZ, Yang L, Magill JM, et al. Assessment of bone marrow plasma cell infiltrates in multiple myeloma: the added value of CD138 immunohistochemistry. Hum Pathol 2007;38(12):1779-87.

[12] Bangerter M, Hildebrand A, Waidmann O, et al. Fine needle aspiration cytology in extramedullary plasmacytoma. Acta Cytol 2000;44(3):287-91.

[13] Foucar K, Raber M, Foucar E, et al. Anaplastic myeloma with massive extramedullary involvement. Report of two cases cancer 1983;51(1):166-74.

[14] Chen HF, Fu WJ, Wang DX, et al. Clinical features of multiple myeloma patients with extramedullary disease: a report of 40 cases from a single center. Zhonghua Xue Ye Xue Za Zhi 2007;28(10):655-8. 